\title{
FAKTOR-FAKTOR YANG BERPENGARUH TERHADAP EFISIENSI USAHATANI PADI LAHAN RAWA DI KABUPATEN CIAMIS
}

\section{FACTORS AFFECTING THE EFFICIENCY OF SWAMP RICE FARMING IN CIAMIS DISTRICT}

\author{
Agus Yuniawan Isyanto*, Sudrajat, Saepul Aziz, Anisa Puspitasari \\ Universitas Galuh, Jl. RE Martadinata No. 150 Ciamis 46274 \\ *E-mail: gusyun69@gmail.com \\ (Diterima 14-06-2020; Disetujui 15-07-2020)
}

\begin{abstract}
ABSTRAK
Penelitian dilaksanakan dengan tujuan untuk mengetahui: (1) Efisiensi usahatani padi lahan rawa pada MT I dan MT II, (2) Perbedaan efisiensi usahatani padi lahan rawa MT I dan MT II, dan (3) Faktor-faktor yang berpengaruh terhadap efisiensi usahatani padi lahan rawa. Penelitian dilaksanakan di Desa Sukanagara Kecamatan Lakbok Kabupaten Ciamis dengan jumlah sampel sebanyak 41 petani. Efisiensi usahatani padi lahan rawa dianalisis dengan menggunakan $\mathrm{R} / \mathrm{C}$ ratio, perbedaan efisiensi dianalisis dengan menggunakan uji $t$, dan faktor-faktor yang mempengaruhi efisiensi usahatani padi lahan rawa dianalisis dengan menggunakan persamaan regresi linier berganda. Hasil penelitian menunjukkan bahwa: (1) Petani yang mencapai efisiensi usahatani padi lahan rawa pada MT I sebanyak 35 orang (85,36\%), sedangkan pada MT II sebanyak 41 orang $(100 \%)$, (2) Terdapat perbedaan yang signifikan antara efisiensi usahatani padi lahan rawa pada MT I dan MT II, dan (3) Luas lahan, modal, pendidikan dan musim tanam berpengaruh signifikan terhadap efisiensi usahatani padi lahan rawa. Sedangkan umur, pengalaman dan jumlah tanggungankeluarga tidak berpengaruh signifikan terhadap efisiensi usahatani padi lahan rawa.
\end{abstract}

Kata kunci: Efisiensi usahatani, lahan rawa

\section{ABSTRACT}

The study aims to determine:: (1) Efficiency of swamp rice farming in planting season I and II, (2) Differences in efficiency of swamp rice farming in planting season I and II, and (3) actors that influence the efficiency of swamp rice farming. The study was conducted in Sukanagara Village, Lakbok Subdistrict, Ciamis District with a total sample of 41 farmers. The efficiency of swamp rice farming is analyzed using the $R / C$ ratio, the difference in efficiency is analyzed using $t$ test, and the factors that influence the efficiency of swamp rice farming are analyzed using multiple linear regression equations. The results showed that: (1) Farmers who achieved efficiency in swamp rice farming in planting season I were 35 people (85.36\%), while in planting season II there were 41 people (100\%), (2) There is a significant difference between the efficiency of swamp rice farming in planting season I and II, and (3) Land area, capital, education and planting season have a significant effect on the efficiency of swamp rice farming. While age, experience and the number of family dependents did not significantly influence the efficiency of swamp rice farming.

Keywords: Farm efficiency, swamp land

\section{PENDAHULUAN}

Pembangunan pertanian bertujuan

untuk meningkatkan produksi sebagai

upaya pemenuhan kebutuhan pangan dalam negeri dan peningkatan kesejahteraan petani (Handayani, 2017). Salah satu tantangan dalam pembangunan pertanian adalah perubahan iklim 
(Effendi dkk, 2014) berupa banjir (Sitanggang dan Judawinata, 2019). dan kekeringan (Sayaka dkk, 2019) yang mengakibatkan kegagalan tanam maupun kegagalan panen (Arinta dan Lubis, 2018).

Produksi pangan nasional belum mampu memenuhi kebutuhan pangan nasional (Ma'ruf dkk, 2019). Produksi pangan nasional selama ini masih bertumpu pada lahan sawah irigasi terutama di Pulau Jawa (Suryana, 2016).

Salah satu upaya peningkatan produksi pangan adalah pemanfaatan lahan marginal (Irwandi, 2015), antara lain lahan rawa (Jalil dkk., 2016) yang luasnya mencapai 33,4 juta hektar (Dewan Riset Nasional, 2012).

Upaya pemanfaatan lahan rawa perlu didukung oleh teknologi budidaya yang memadai (Susilawati dkk, 2016) mengingat usahatani pada lahan rawa memiliki risiko yang tinggi (Zakirin $\mathrm{dkk}$, 2013).

Produktivitas padi lahan rawa masih tergolong rendah (Suparwoto, 2019), dan pendapatan pada usahatani padi rawa lebih rendah dibandingkan pendapatan pada usahatani padi sawah (Asriani dkk, 2020).

Efisiensi suatu usaha salah satunya dapat diukur dengan menggunakan analisis R/C (Santosa dkk, 2013; Kamisi, 2013). Analisis R/C ratio dihitung dengan membandingkan antara penerimaan (revenue) dengan biaya total (cost) (Ma'ruf dkk, 2019).

Penelitian yang terkait efisiensi menunjukkan bahwa faktor-faktor yang memengaruhi efisiensi antara lain: lahan (Isyanto, 2011), pendidikan dan akses terhadap kredit (Isyanto et al, 2013), pelatihan dan pengalaman (Isyanto dkk, 2016)., modal dan tenaga kerja keluarga (Isyanto dan Iwan, 2017), umur dan akses terhadap kredit (Maemunah dan Isyanto, 2017), ukuran keluarga (Widi dan Isyanto, 2019).

Berdasarkan uraian di atas, maka penelitian ini dilaksanakan dengan tujuan untuk mengetahui: (1) Efisiensi usahatani padi lahan rawa pada MT I dan MT II, (2) Perbedaan efisiensi usahatani padi lahan rawa MT I dan MT II, dan (3) Faktor-faktor yang berpengaruh terhadap efisiensi usahatani padi lahan rawa.

\section{METODE PENELITIAN}

Penelitian dilaksanakan di Desa Sukanagara Kecamatan Lakbok yang merupakan satu-satunya lahan rawa di Kabupaten Ciamis. Ukuran sampel 41 orang yang diambil dengan menggunakan rumus Slovin dengan error margin 10\% 
dari ukuran populasi sebanyak 70 petani. Data yang digunakan merupakan data usahatani padi lahan rawa musim tanam (MT) I dan II tahun 2018/2019.

Penelitian dilaksanakan dengan pendekatan kuantitatif. Menurut Mulyadi (2011), pendekatan kuantitatif dilakukan untuk mengetahui apakah terdapat korelasi ataupun pengaruh variabel bebas (independent variable) terhadap variabel terikat (dependent variable).

Penelitian dilaksanakan dengan menggunakan metode survey. Menurut Singarimbun dan Effendi (1989), penelitian survai adalah penelitian yang mengambil sampel dari satu populasi dan menggunakan kuesioner sebagai alat pengumpulan data yang pokok (Singarimbun dan Effendi, 1989).

Efisiensi usahatani padi lahan rawa didekati dengan menggunakan analisis $\mathrm{R} / \mathrm{C}$ dengan persamaan sebagai berikut Triastono, dkk (2013):

$\mathrm{E}=\mathrm{R} / \mathrm{C}$

Dimana:

$\mathrm{E}=$ Efisiensi usaha

$\mathrm{R}=$ Return (Penerimaan) (Rp)

$\mathrm{C}=\operatorname{Cost}$ (Biaya) (Rp)

Menurut Santosa dkk (2013), kriteria efisiensi usaha dengan menggunakan rasio $\mathrm{R} / \mathrm{C}$ adalah sebagai berikut: efisiensi jika $\mathrm{R} / \mathrm{C}>1$, belum efisien jika $\mathrm{R} / \mathrm{C}=1$, dan tidak efisien jika
$\mathrm{R} / \mathrm{C}<1$. Menurut Wibowo dkk (2013), efisiensi tercapai jika $\mathrm{R} / \mathrm{C}>1$, keuntungan bernilai nol jika $\mathrm{R} / \mathrm{C}=1$, dan inefisiensi jika $\mathrm{R} / \mathrm{C}<1$.

Analisis perbedaan efisiensi usahatani padi lahan rawa MT I dan II dianalisis dengan menggunakan uji $\mathrm{t}$ tidak berpasangan (unpaired t-test). Mengacu pada Handayani dkk (2017), uji beda dianalisis dengan menggunakan varians, sedangkan uji homogenitas varians dengan menggunakan nilai FBahren Fisher. Rumus uji $t$ yang digunakan adalah sebagai berikut:

$$
t=\frac{X_{1}-X_{2}}{\sqrt{\frac{S_{1}^{2}}{n_{1}}+\frac{S_{2}^{2}}{n_{2}}}}
$$

Dimana:

$\mathrm{X}_{1}=$ Rata-rata efisiensi usahatani MT I

$\mathrm{X}_{2}$ = Rata-rata efisiensi usahatani MT II

$\mathrm{S}_{1}=$ Varian MT I

$\mathrm{S}_{2}=$ Varian MT II

$\mathrm{n}_{1}=$ Sampel MT I

$\mathrm{n}_{2}=$ Sampel MT II

Faktor-faktor yang berpengaruh terhadap efisiensi usahatani padi lahan rawa dianalisis dengan menggunakan regresi linier berganda dengan persamaan sebagai berikut:

$$
\begin{gathered}
\mathrm{Y}=\mathrm{a}+\mathrm{b}_{1} \mathrm{X}_{2}+\mathrm{b}_{2} \mathrm{X}_{2}+\mathrm{b}_{3} \mathrm{X}_{3}+\mathrm{b}_{4} \mathrm{X}_{4} \\
+\mathrm{b}_{5} \mathrm{X}_{5}+\mathrm{b}_{6} \mathrm{X}_{6}+\mathrm{b}_{7} \mathrm{D}
\end{gathered}
$$

Dimana:

$\mathrm{Y}=$ Efisiensi usaha $(\mathrm{R} / \mathrm{C})$

$\mathrm{X}_{1}=$ Lahan (ha)

$\mathrm{X}_{2}=$ Modal (Rp)

$\mathrm{X}_{3}=$ Umur (tahun)

$\mathrm{X}_{4} \quad=$ Pendidikan (tahun) 
$\mathrm{X}_{5} \quad=$ Pengalaman (tahun)

$\mathrm{X}_{6}=$ Jumlah tanggungan keluarga

(orang)

$\mathrm{D}=$ Variabel dummy musim tanam (bernilai 1 jika MT I, dan 0 jika lainnya)

a $\quad=$ konstanta

$\mathrm{b}_{1-7}=$ koefisien regresi
HASIL DAN PEMBAHASAN

Efisiensi Usahatani Padi Lahan Rawa

Efisiensi usahatani padi lahan rawa yang dianalisis dengan menggunakan $\mathrm{R} / \mathrm{C}$ ratio menunjukkan hasil sebagaimana terlihat pada Tabel 1.

Tabel 1. Efisiensi Usahatani Padi Lahan Rawa MT I dan II

\begin{tabular}{cccccc}
\hline \multirow{2}{*}{ No. } & \multirow{2}{*}{ Efisiensi Usaha } & \multicolumn{2}{c}{ MT 1 } & \multicolumn{2}{c}{ MT 2 } \\
\cline { 2 - 6 } & & Petani (orang) & $\mathbf{\%}$ & Petani (orang) & \% \\
\hline 1 & $<1$ & 3 & 7,32 & 0 & 0,00 \\
2 & 1 & 3 & 7,32 & 0 & 0,00 \\
3 & $>1$ & 35 & 85,36 & 41 & 100,00 \\
\hline & Jumlah & $\mathbf{4 1}$ & $\mathbf{1 0 0 , 0 0}$ & $\mathbf{4 1}$ & $\mathbf{1 0 0 , 0 0}$ \\
\hline
\end{tabular}

Sumber: Analisis Data Primer, 2019

Tabel 1 menunjukkan bahwa petani yang mencapai efisiensi usahatani padi lahan rawa pada MT I sebanyak 35 orang $(85,36 \%)$, sedangkan pada MT II sebanyak 41 orang $(100 \%)$. Hal ini menunjukkan bahwa kegiatan penyuluhan dan bimbingan teknis sebaiknya difokuskan pada MT I.

Rata-rata R/C pada MT I sebesar 1,32; sedangkan pada MT II sebesar 1,75. Hal ini menunjukkan bahwa usahatani padi lahan rawa telah mencapai efisiensi serta mampu memberikan keuntungan kepada petani. Setiap Rp 1 biaya yang dikeluarkan oleh petani akan menghasilkan penerimaan sebesar $\mathrm{Rp}$ 1,32 pada MT I dan Rp 1,75 pada MT II. Dengan demikian, pendapatan yang diperoleh petani pada MT I sebesar Rp 0,32; dan pada MT II sebesar Rp 0,75. Menurut Alfrida dan Noor (2018), pendapatan petani merupakan salah satu tolok ukur tingkat kesejahteraan petani.

\section{Perbedaan Efisiensi Usahatani Padi Rawa}

Perbedaan efisiensi usahatani padi lahan rawa MT I dan MT II diuji dengan menggunakan uji t tidak berpasangan sebagaimana terlihat pada Tabel 2.

Tabel 2 menunjukkan nilai signifikansi sebesar $0,000<0,0005$ sehingga dapat disimpulkan adanya perbedaan yang signifikan antara efisiensi usahatani padi lahan rata pada MT I dan MT II. 
Tabel 2. Uji Perbedaan Efisiensi Usahatani Padi Lahan Rawa MT I dan MT II

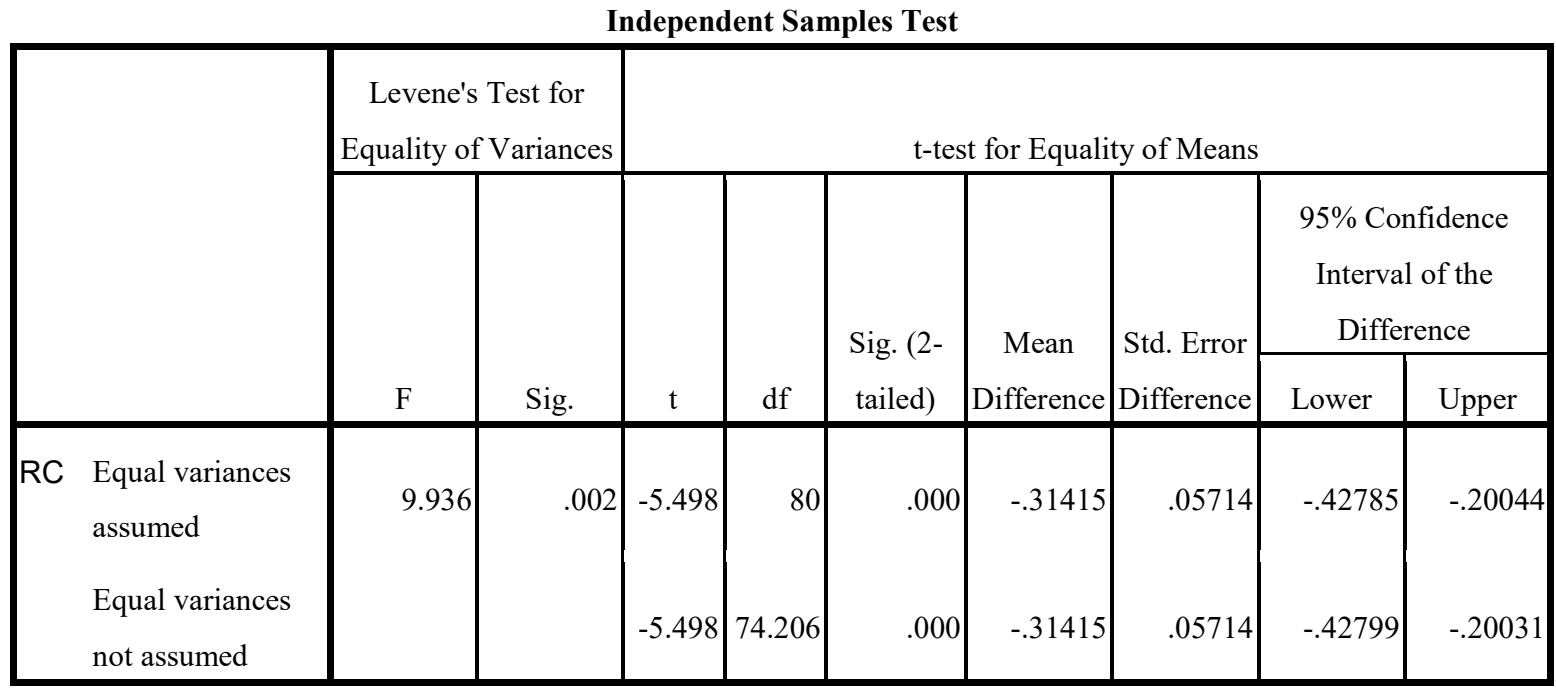

Faktor-faktor yang Berpengaruh

\section{Terhadap Efisiensi Usahatani}

Faktor-faktor yang berpengaruh terhadap efisiensi usahatani padi lahan rawa dianalisis dengan menggunakan model regresi linier berganda sebagaimana terlihat pada Tabel 3 .

Tabel 3. Faktor-faktor yang Berpengaruh Terhadap Efisinsi Usahatani Padi Lahan Rawa

\begin{tabular}{lccc}
\hline \multicolumn{1}{c}{ Variabel } & Nilai Parameter & Standar Deviasi & t-hit \\
\hline Konstanta & 11,374 & 2,577 & $4,414^{*}$ \\
Lahan & 0,669 & 0,170 & $3,924^{*}$ \\
Modal & $-0,632$ & 0,161 & $-3,914^{*}$ \\
Umur & $-0,176$ & 0,157 & $-1,118$ \\
Pendidikan & $-0,277$ & 0,114 & $-2,440^{* *}$ \\
Pengalaman & 0,110 & 0,071 & 1,546 \\
Jumlah tanggungan keluarga & $-0,011$ & 0,061 & $-0,188$ \\
Dummy musim tanam & $-0,220$ & 0,036 & $-6,056^{*}$ \\
\hline $\mathrm{R}^{2}$ & 0,452 & & \\
F-hit & $8,728^{*}$ & & \\
\hline Sumat & & & \\
\hline
\end{tabular}

Sumber: Analisis Data Primer, 2019

Keterangan: *, ** signifikan pada $1 \%, 5 \%$

Nilai koefisien determinasi $\left(\mathrm{R}^{2}\right)$ sebesar 0,452 menunjukkan bahwa efisiensi usahatani padi lahan rawa dapat dijelaskan sebesar 45,20\% oleh variabelvariabel yang dimasukkan ke dalam model, sedangkan sisanya sebesar
$54,80 \%$ dijelaskan oleh variabel lain yang tidak dimasukkan ke dalam model.

Nilai F-hit sebesar 8,728 pada taraf nyata $1 \%$ menunjukkan bahwa seluruh variabel yang ada di dalam model secara simultan berpengaruh sangat signifikan 
terhadap efisiensi usahatani padi lahan rawa.

Pengujian secara parsial menunjukkan bahwa faktor yang berpengaruh positif dan signifikan terhadap efisiensi usahatani padi lahan rawa adalah lahan. Faktor-faktor yang berpengaruh negatif dan signifikan terhadap efisiensi usahatani padi lahan rawa adalah modal, pendidikan dan dummy musim tanam. Umur, pengalaman dan jumlah tanggungan keluarga tidak berpengaruh signifikan terhadap efisiensi usahatani padi lahan rawa.

Luas lahan berpengaruh sangat signifikan terhadap efisiensi usahatani padi lahan rawa. Koefisien regresi bertanda positif menunjukkan bahwa semakin luas lahan yang dikelola oleh petani maka semakin meningkat efisiensi yang dicapai pada usahatani padi lahan rawa tersebut. Penelitian Arimbawa dkk (2017) menunjukkan bahwa luas lahan berpengaruh signifikan terhadap produktivitas petani padi, dan penelitian Isyanto dkk (2016) menunjukkan bahwa produktivitas berpengaruh signifikan terhadap efisiensi usaha.

Modal berpengaruh sangat signifikan terhadap efisiensi usahatani padi lahan rawa. Koefisien regresi bertanda negatif menunjukkan bahwa semakin besar modal yang digunakan dalam usahatani padi lahan rawa, maka akan semakin menurun efisiensi yang dicapai pada usahatani padi lahan rawa tersebut. Peningkatan penggunaan modal yang tidak diikuti dengan peningkatan produksi akan menurunkan pendapatan petani yang berpengaruh terhadap efisiensi.

Umur tidak berpengaruh signifikan terhadap efisiensi usahatani padi lahan rawa. Koefisien regresi bertanda negatif menunjukkan bahwa semakin bertambahnya umur petani akan menurunkan tingkat efisiensi usahatani padi lahan rawa. Menurut Sujaya dkk (2018), bertambahnya umur petani akan menurunkan kemampuan fisik dan berpikir petani yang berdampak terhadap penurunan produktivitas yang akan mempengaruhi tingkat efisiensi usahatani.

Pendidikan berpengaruh signifikan terhadap efisiensi usahatani padi lahan rawa. Koefisien regresi bertanda negatif menunjukkan bahwa bertambahnya pendidikan yang ditempuh petani akan menurunkan tingkat efisiensi usahatani padi lahan rawa. Penelitian Namah dan Sinlae (2012) menunjukkan bahwa pendidikan berpengaruh negatif terhadap pendapatan petani yang menunjukkan 
adanya penurunan efisiensi. Peningkatan pendidikan petani yang tidak sesuai dengan usahatani yang dikelolanya tidak akan memberikan kontribusi yang signifikan.

Pengalaman tidak berpengaruh signifikan terhadap efisiensi usahatani padi lahan rawa. Koefisien regresi bertanda positif menunjukkan bahwa bertambahnya pengalaman akan meningkatkan tingkat efisiensi usahatani padi lahan rawa. Menurut Zuriani (2017), petani yang lebih berpengalaman memiliki kemampuan dalam mengelola usahataninya sehingga dapat menghasilkan produksi yang lebih banyak yang berdampak terhadap peningkatan efisiensi.

Jumlah tanggungan keluarga tidak berpengaruh signifikan terhadap efisiensi usahatani padi lahan rawa. Koefisien regresi bertanda negatif menunjukkan bahwa bertambahnya ukuran keluarga akan menurunkan tingkat efisiensi usahatani padi lahan rawa. Penelitian Rizkiyah dkk (2014) menunjukkan bahwa jumlah tanggungan keluarga pengaruh negatif terhadap efisiensi. Semakin banyak jumlah tanggungan keluarga, maka akan semakin banyak kebutuhan hidup keluarga sehingga petani mencari sumber pendapatan di luar usahatani. Hal ini menyebabkan penurunan curahan waktu kerja pada usahatani yang mengakibatkan penurunan produksi yang berdampak pada penurunan efisiensi.

Musim tanam berpengaruh sangat signifikan terhadap efisiensi usahatani padi lahan rawa. Koefisien regresi bertanda negatif menunjukkan bahwa efisiensi usahatani padi lahan rawa pada MT II lebih tinggi dibandingkan MT I. MT I dilaksanakan pada bulan JanuariApril dimana curah hujan lebih tinggi dibandingkan MT II yang dilaksanakan pada bulan Juli-Oktober. Tingginya curah hujan pada MT I menyebabkan lebih rendahnya produksi yang dihasilkan dibandingkan hasil produksi pada MT II yang berdampak terhadap efisiensi. Penelitian Suharyanto dkk (2015) secara substantif menunjukkan bahwa curah hujan yang tinggi mengakibatkan menurunnya produktivitas usahatani padi.

\section{KESIMPULAN DAN SARAN}

\section{Kesimpulan}

(1) Petani yang mencapai efisiensi usahatani padi lahan rawa pada MT I sebanyak 35 orang $(85,36 \%)$, sedangkan pada MT II sebanyak 41 orang $(100 \%)$. 
(2) Terdapat perbedaan yang signifikan antara efisiensi usahatani padi lahan rawa pada MT I dan MT II.

(3) Luas lahan, modal, pendidikan dan musim tanam berpengaruh signifikan terhadap efisiensi usahatani padi lahan rawa. Sedangkan umur, pengalaman dan jumlah tanggungan keluarga tidak berpengaruh signifikan terhadap efisiensi usahatani padi lahan rawa.

\section{Saran}

Berdasarkan kesimpulan penelitian, maka disarankan agar kegiatan penyuluhan dan bimbingan teknis kepada petani padi lahan rawa difokuskan pada MT I agar terjadi peningkatan efisiensi usahatani tersebut.

\section{DAFTAR PUSTAKA}

Alfrida, A. dan Noor, T.I. (2018). Analisis Pendapatan dan Tingkat Kesejahteraan Rumah Tangga Petani Padi Sawah Berdasarkan Luas Lahan. Jurnal Ilmiah Mahasiswa Agroinfo Galuh, 4(3): 803-810.

Arimbawa, P.D dan Widanta, A.A.B.P. (2017). Pengaruh Luas Lahan, Teknologi dan Pelatihan Terhadap Pendapatan Petani Padi dengan Produktivitas Sebagai Variabel Intervening di Kecamatan Mengwi. E-Jurnal Ekonomi Pembangunan Universitas Udayana, 6(8): 16011627.
Arinta, K. dan Lubis, I. (2018). Pertumbuhan dan Produksi Beberapa Kultivar Padi Lokal Kalimantan. Bul. Agrohorti, 6(2): 270-280.

Asriani, W., Noor, T.I. dan Isyanto, A.Y. (2020). Analisis Perbedaan Pendapatan Pada Usahatani Padi Sawah Dan Padi Rawa (Suatu Kasus di Desa Sukanagara Kecamatan Lakbok Kabupaten Ciamis). Jurnal Ilmiah Mahasiswa Agroinfo Galuh, 7(1): 160-165.

Dewan Riset Nasional. (2012). Bunga Rampai Pemikiran Dewan Riset Nasional 2012: Riset Untuk Keunggulan Dan Daya Saing Bangsa. Jakarta.

Effendi, D.S., Abidin, Z. dan Prastowo, B. (2014). Model Percepatan Pengembangan Pertanian Lahan Rawa Lebak Berbasis Inovasi. Pengembangan Inovasi Pertanian, 7(4): 177-186.

Handayani, S.A., Effendi, I. dan Viantimala, B. (2017). Produksi dan Pendapatan Usahatani Padi di Desa Pujo Asri Kecamatan Trimurjo Kabupaten Lampung Tengah. JIIA, 5(4): 422-429.

Irwandi, D. (2015). Strategi Peningkatan Pemanfaatan Lahan Rawa Pasang Surut dalam Mendukung Peningkatan Produksi Beras di Kalimantan Tengah. Agriekonomika, 4(1): 97-106.

Isyanto, A.Y, Semaoen, M.I, Hanani, N., \& Syafrial. (2013). Measurement of Farm Level Efficiency of Beef Cattle Fattening in West Java Province, Indonesia. Journal of Economics and Sustainable Development, 4(10), 100-105.

Isyanto, A.Y. 2011. Faktor-Faktor yang Mempengaruhi Inefisiensi Teknik pada Usahatani Padi di Kabupaten Ciamis. Jurnal Cakrawala Galuh, 1(5): 30-40. 
Isyanto, A.Y. dan Sugianto, I. (2017).

Faktor-faktor yang Berpengaruh Terhadap Efisiensi Usaha Penggemukan Sapi Potong di Kabupaten Ciamis. Prosiding Seminar Nasional Hasil Penelitian Pertanian VI 2016, FakultasPertanian Universitas Gadjah Mada. pp. 235-239.

Isyanto, A.Y., Sudrajat dan Iskandar, M. (2016). Faktor-faktor yang Berpengaruh Terhadap Efisiensi Usaha Ayam Sentul di Kabupaten Ciamis. Mimbar Agribisnis, 3(1): 197-202.

Jalil, M., Sakdiah, H., Deviana, E. dan Akbar, I. (2016). Pertumbuhan dan Produksi Beberapa Varietas Padi (Oryza Sativa L) pada Berbagai Tingkat Salinitas. Jurnal Agrotek Lestari, 2(2): 63-74.

Kamisi, H.L. (2013). Analisis Usahatani Bayam (Studi Kasus di Kelurahan Sasa Kecamatan Ternate Selatan Kota Ternate). Jurnal Ilmiah Agribisnis dan Perikanan (Agrikan UMMU-Ternate), 6(1): 58-63.

Ma'ruf, M.I., Kamaruddin, C.A. dan Muharief, A. (2019). Analisis Pendapatan dan Kelayakan Usahatani Padi di Kecamatan Pitu Riawa Kabupaten Sidrap. Jurnal Sosial Ekonomi Pertanian, 15(3): 193-204.

Maemunah, S. dan Isyanto, A.Y. (2017). Faktor Penentu Inefisiensi Teknis Pada Usaha Ternak Kambing Peranakan Ettawa. Mimbar Agribisnis: Jurnal Pemikiran Masyarakat Ilmiah Berwawasan Agribisnis, 3(2): 169-184.

Mulyadi, M. (2011). Penelitian Kuantitatif Dan Kualitatif Serta Pemikiran Dasar Menggabungkannya. Jurnal Studi Komunikasi dan Media, 15(1): 127138.
Namah, C.N. dan Sinlae, D.V. (2012). Faktor-faktor yang Mempengaruhi Produksi dan Pendapatan Usahatani Jeruk Keprok Soe di Kabupaten Timor Tengah Selatan. Partner, 19(1): 14-25.

Rizkiyah, N., Syafrial dan Hanani, N. (2014). Faktor-faktor yang Mempengaruhi Efisiensi Teknis Usahatani Kentang (Solanum Tuberosum L) dengan Pendekatan Stochastic Production Frontier (Kasus Desa Sumber Brantas Kecamatan Bumiaji Kota Batu). Habitat, XXV(1): 25-31.

Santosa, S.I., Setiadi, A., dan Wulandari, R. (2013). Analisis Potensi Pengembangan Usaha Peternakan Sapi Perah dengan Menggunakan Paradigma Agribisnis di Kecamatan Musuk Kabupaten Boyolali. Buletin Peternakan 37(2): 125-135.

Sayaka, B, Wahida dan Sudaryanto, T. (2019). Daya Tahan Rumah Tangga Petani Terhadap Kekeringan di Jawa Timur Dan Nusa Tenggara Barat. Jurnal Agro Ekonomi, 37(1): 61-78.

Singarimbun, M. dan Effendi, S. (1989). Metode Penelitian Survai. Jakarta: LP3S.

Sitanggang, S.S. dan Judawinata, M.G. (2019). Analisis Usahatani Padi Rawa (Studi Kasus di Desa Sukanagara Kecamatan Lakbok Kabupaten Ciamis). Jurnal Ilmiah Mahasiswa Agroinfo Galuh, 6(1): 154-167.

Suharyanto, Mulyo, J.H., Darwanto, D.H. dan Widodo, S. (2015). Analisis Produksi dan Efisiensi Pengelolaan Tanaman Terpadu Padi Sawah di Provinsi Bali. Penelitian Pertanian Tanaman Pangan, 34(2): 131-144.

Sujaya, D.H., Hardiyanto, T. dan Isyanto, A.Y. (2018). Faktor-faktor yang Berpengaruh Terhadap 
Produktivitas Usahatani Mina Padidikota Tasikmalaya. Mimbar Agribisnis: Jurnal Pemikiran Masyarakat Ilmiah Berwawasan Agribisnis, 4(1):25-39.

Suparwoto. (2019). Produksi dan Pendapatan Usahatani Padi di Lahan Rawa Lebak Kabupaten Ogan Komering Ilir Sumatera Selatan. Journal on SocioEconomics of Agriculture and Agribusiness, 13(1): 51-60.

Suryana. (2016). Potensi Dan Peluang Pengembangan Usaha Tani Terpadu Berbasis Kawasan di Lahan Rawa. Jurnal Litbang Pertanian, 35(2): 57-68.

Susilawati, A., Nursyamsi, D. dan Syakir, M. (2016). Optimalisasi Penggunaan Lahan Rawa Pasang Surut Mendukung Swsembada Pangan Nasional. Jurnal Sumberdaya Lahan, 10(1): 51-64.

Triastono, H., Indraji, M., dan Mastuti, S. 2013. Pengaruh Faktor Sosial Ekonomi Terhadap Pendapatan dan Efisiensi Usaha Peternak Kelinci di Kabupaten Banyumas. Jurnal Ilmiah Peternakan, 1(1): 25-30.
Wibowo, D., Muatip, K., dan Aunurohman, H. 2013. Analisis Efisiensi Usaha dan Kontribusi Pendapatan Peternak Kelinci di Kabupaten Banyumas. Jurnal Ilmiah Peternakan, 1(3): 821-826.

Widi, R.H. and Isyanto, A.Y. 2020. Determinants of Technical Inefficiencies of Sweet Potato Farming in Kuningan District. Proceedings of The International Conference on Agriculture, Social Sciences, Education, Technology and Health (ICASSETH 2019). pp. 118-120.

Zakirin, M., Yurisinthae, E. dan Kusrini, N. (2013). Analisis Risiko Usahatani Padi pada Lahan Pasang Surut di Kabupaten Pontianak. Jurnal Social Economic of Agriculture, 2(1): 75-84.

Zuriani. (2017). Keterkaitan dan Dampak Karakteristik Sosial Petani Terhadap Produksi Padi di Kabupaten Aceh Utara. Jurnal Agrifo, 2(1): 29-40. 